\title{
Alúna: una experiencia de autocualificación docente in-situ. Estudios de caso en formación del profesorado.
}

Maryi Valderrama, Irma Moreno, Mauricio Müller, Luis Alberto Torres ${ }^{\text {' }}$

Grupo Alüna de Investigación Pedagógica
Este texto pretende mostrar el diseño metodológico resultante de una experiencia particular de investigación pedagógica en aula, que apunta a la cualificación de los docentes a partir de su propia práctica. Se centra en dos problemas principales: ¿qué son la lectura y la escritura en el aula? y ¿cómo cualificar la práctica pedagógica para formar reales lectores y escritores? Lejos de querer ser una radiografía que da cuenta de la experiencia, estas líneas buscan compartir con otros lectores algunas de las conclusiones a las que el grupo de investigación ha llegado durante el transcurso de la experiencia. Se analizan las actividades metodológicas realizadas, enmarcándolas específicamente dentro de la implementación de la investigación, las concepciones y los dos obstáculos que se consideraron pertinentes al tema del escrito aclarando que no fueron los únicos encontrados-: así como señalar, sin desarrollar en su totalidad, algunos de los problemas prácticos que aparecieron durante el proceso formativo $y$ de conformación del equipo de trabajo.

Lsta experiencia se viene desarrollando ciesde el año 2000 , y en la actu. lidad ha dado pie para la conformación de un equipo permanente de investigación docente conformado por los maestros Maryi Valderrama, Irma Moreno, Mauricio Müller y l uis Alberto Torres. Todos ellos ejercen su práctica en el nivel de bachillerato y son maestros en aula actualmente activos. El grupo de investigación conserva el nombre del proyecto inicial: Alúna. El texto presentado fue escrito por Maryi Valderrama, con base en los documentos del proyecto, para la revista Investigación en la Escuela. Estudios de caso en la formación del profesorado.
El espíritu que convocó a los maestros que finalmente conformaron el equipo de trabajo fue uno sólo: el de hacer investigación sobre sus propias prácticas para evaluarlas y mejorarlas. No se tenía 
mayor experiencia en investigación en aula, antes no se había conformado un equipo de trabajo, cada uno de los maestros ejercía en una delerminada disciplina curricular, que en nuestra cultura escolar se presentan como estructuras separadas muy rígidas en el trabajo cotidiano en la Escuela. Nos unía el problema que la lectura y la escritura representaba para cada una de las prácticas.

Es así como maestros de las disciplinas de Matemáticas, Ciencias Naturales, Educación Física, Educación Religiosa, Tecnología e Informática, Inglés, Ciencias Sociales y Filosofía, junto con una docente coordinadora administrativa, desarrollaron un proyecto interdisciplinar de investigación en el aula en torno al problema de la formación de lectores y escritores Ilamado Alúna², inicialmente con los estudiantes del grado décimo de educación Media vocacional, y posteriormente con los estudiantes de grados sexto a undécimo de la Educación Básica y Media, del Colegio Abraham Lincoln, de Bogotá.

Además del problema de investigación, el equipo tuvo que resolver un problema más urgente al comenzar a trabajar: el encontrar un lenguaje común que permitiera el encuentro de los lenguajes y pensamientos divergentes de las disciplinas participantes y que propiciara la consolidación de un equipo de trabajo. Así nacieron las metáforas que fueron el instrumento de "traslación", el cual se convirtió en el eje comunicativo de la experiencia.

\section{Nuestro punto de partida. Las metáforas}

Partimos de la metáfora del laberinto para describir el camino de hacer investigación sobre las propias prácticas, del que no se conoce el mapa y que necesariamente hay que recorrer para aprehenderlo: así que se tendrá que devolver lo andado cuando el

\footnotetext{
Fvocando los principios de vida del pueblo indigena Kogi que habitan la Sierra Nevada de Santa Marta. En forma de verbo la palabra alúna, alúni, alünyi significa querer, desear, amar, cohabitar, gustar: na-arlúnye: me gusta. La raiz de la palabra se deriva posiblemente de un concepto de fertilización o creación: júla-clase, especie, sula-semilla, reton̄o, cl pri mer tallo que nace; jele-maduro, séiji-ser, existir. Aunque la palabra amor no existe en el idioma Kogi, ella se traduce, al preguntar por ella, con la palabra alúna.
}

camino conduzca a una sin salida y escoger otra opción. Luego se introdujo la metáfora de la telaraña de significación en la que todos los seres humanos estamos inmersos y de la cual dependemos para nuestro desempeño en el mundo. Somos como las arañas que tejen y destejen los signos y los símbolos que conforman la telaraña. La metáfora de los espejos surge cuando entra el Otro en las prácticas en aula para retroalimentarlas, para devolver imágenes de ellas. La cámara de vídeo contribuye a que esas imágenes de retorno sean menos fragmentadas, y la lectura que hace el par, el otro maestro es la imagen que nos devuelve el espejo. La práctica pedagógica es una "cierta manera de hacer en el aula", que se devela mejor en la conjunción de las miradas externas y las internas: los ojos que se miran a sí mismos en el espejo. Hablamos entonces de un observador observado, un observador que observa a otros y se observa a sí mismo; un observador que también puede, intencionalmente, observar de qué manera observa y reflexionar acerca de lo que eso le dice sobre su actuar. Todos somos actores en el escenario del mundo, nos recuerda Shakespeare, y qué dimensión de veracidad encuentra esta afirmación en el aula. El aula es el escenario de la puesta en escena de los saberes pedagógicos y de las interacciones entre los actores. $Y$ de la catarsis resultante debe producirse conocimiento. Así nació la metáfora del teatro.

La metáfora del teatro forma parte de la historia de las ciencias sociales. La primera forma de reflexión sobre la sociedad y sus complejos vericuetos fue el teatro griego. Y, desde entonces, las categorías propias del teatro hacen carrera en todos los intentos de autocomprendernos como seres en interacción. Categorías como escenario, actor, acto, papel, libreto, autor, bambalinas, consueta, telón de fondo, forman parte del discurso sociológico, antropológico y lingüístico de la ciencia occidental.

En la búsqueda de un nombre diferente para denominar nuestra actividad en el aula, marcada por la expresión "dictar clase", con sus inevitables connotaciones de discurso unidireccional, de razón monológica, de discurso autoritario e incluso de "dictadura", nos fuimos encontrando, sin quererlo, 
con la metáfora del teatro. Empezamos a referimos al aula como nuestro escenario natural y nos fuimos autodefiniendo como actores.

Consecuentes con esta metáfora, comenzamos a entender que la clase no es otra cosa que un "libreto", elaborado y puesto en escena por nosotros, los maestros. Es el libreto el que determina qué tipo de drama va a representarse, cuáles son los papeles más importantes y cuáles, finalmente, serán los actores que lo pondrán en escena. Es el libreto el que determina la escenografía, los telones de fondo, la luminotecnia y el vestuario de los actores. Es decir: las condiciones y los instrumentos de la actuación. Todos los libretos son elaborados de antemano, aunque nosotros, algunas veces, los improvisemos sobre la marcha. El aula es el escenario en donde esos libretos se validan o pierden vigencia.

Cada persona en ese escenario es un actor con un papel específico. La tradición autoritaria le acuerda un papel protagónico al maestro y un papel secundario y pasivo a los estudiantes. Pero no necesariamente debe ser así, el teatro moderno está preocupado por incorporar el "público" a la actuación. Y podría pensarse que los estudiantes pueden desempeñar un papel protagónico, según el tipo de libreto elaborado por el maestro. Si este diseña un libreto en el que se reserva el papel protagónico, la responsabilidad de la puesta en escena es exclusivamente suya. Pero si diseña un libreto en el que traslada el protagonismo a los estudiantes, la responsabilidad de poner en escena la obra corresponde a estos últimos. $Y$, según el caso, el libreto mismo puede ser ampliado y corregido por los estudiantes.

Los maestros hemos subvalorado la importancia del libreto. Unas veces porque no le hemos dedicado el tiempo que se merece su elaboración, otras porque lo hemos improvisado sobre la marcha, con un poco de irresponsabilidad. $Y$ otras veces porque nos hemos concentrado en el contenido del drama, descuidando las condiciones y los instrumentos de actuación. Con frecuencia hemos vivido la experiencia de que un libreto, preparado con la suficiente dedicación y buena voluntad, es no sólo cuestio- nado sino transformado en el aula misma: una pregunta inesperada, una inquietud naciente, un nuevo interés, una dificultad, cambia por completo lo que se había planeado. Es entonces cuando reconocemos la importancia de la planeación y la previsión de los factores que pueden aparecer durante la puesta en escena, a sabiendas de que nunca se podrán cubrir todas las posibilidades. En todo caso el diseño del libreto se revela como algo de fundamental importancia para la cualificación de nuestras prácticas.

Le hemos atribuido un gran valor a esta metáfora, no solo porque facilitó la comunicación entre especialistas de diferentes disciplinas, sino especialmente porque cuadra muy bien con una epistemología no positivista de la práctica, que sustituye la racionalidad técnica por la racionalidad constructivista. Casi sin darnos cuenta, la metáfora nos ha trasladado a otra concepción de la práctica pedagógica, en donde el libreto tiene la prioridad lógica sobre la puesta en escena, y en donde el proceso de enseñanza-aprendizaje puede ser preconfigurado desde el lenguaje (diseño), y ser sometido a discusión antes de ponerlo en escena, como si se tratara de un proceso de experimentación.

A manera de ilustración, citamos el texto de la investigadora Astrid Torregroza, docente del área de matemáticas, en su documento Paper Dos, en el que reconstruye apartes de la metáfora del teatro:

En mi diseño escrito número uno utilicé las categorias y después de tanto guerrear con ellas reconozco que son las que le dan una estructura lógica al diseño y las que lo hacen más fácil de ser rumiado por el lector. Pero pienso que le quitan ese encanto a la obra, o sea, que para que ese encanto permanezca el diseño debe ser el libreto que al ponerio en escena se debe llenar de la magia que le inyecte su creador. Ese creador que es a su vez actor, debe tener la facilidad de interpretar diferentes personajes según lo amerite la acción en la obra. Hago este paralelo con el hecho de tener que ser el militar, el cuate o el 
guía en la misma clase, o de repente ser invisible y dejar que los protagonistas principales sean los estudiantes. No es conveniente para el desarrollo de la obra que el maestro represente siempre el mismo personaje; si siempre es el militar, la obra se llamaria la dictadura; si siempre es el cuate, la obra se llamaría la demagogia; si siempre es el guia, la obra se llamaria la excursión; si siempre está invisible, la obra se llamaría los abandonados, ¿Cómo se debería llamar la obra donde la acción principal es la creación de valores, muchas escenas estân llenas de aprendizaje y los prolagonistas son personificados por maestros o estudiantes?

Simultánea a la construcción de las metáforas, el trabajo exigió la definición de un procedimiento metodológico que nos permitiera abordar la investigación. Si se examinan con detención los pasos que estructuran este procedimiento metodológico, se puede concluir que hay una lógica interna que corresponde a otra epistemología de la práctica. Para mejorar la práctica no privilegiamos la evaluación de la práctica, sino el diseño de la práctica. No privilegiamos los resultados de la práctica sino la planificación del proceso. Sólo en un momento posterior a la puesta en escena volvemos sobre ésta, pero no propiamente para evaluarla, sino para reconstruirla.

\section{Tres principios}

Son de carácter pragmático, y los hemos seleccionado para elaborar nuestra metodología:

- Aprender haciendo. Tomado del pedagogo norteamericano John Dewey que, para los efectos de nuestro proyecto, lo traducimos de la siguiente manera: sólo se aprende a investigar investigando.

- Mejorar el hacer reflexionando. Tomado de E. Durkheim, para el cual la pedagogía no es otra cosa que una "cierta manera de reflexionar" sobre los problemas de la práctica educativa.
- Potenciar la reflexión mediante la interlocución entre pares. Valora el trabajo en equipo y tiene antecedentes en la metodología TED, diseñada por los investigadores del PIIE (Proyecto Interdisciplinario de Investigación Educativa, Santiago de Chile) pero también en otras corrientes pedagógicas, como la pedagogía institucional (Lourau).

Estas serían, entonces las etapas del trabajo de investigación:

\section{Diseñar}

La epistemología de la práctica que aquí hemos adoptado, más cercana a las disciplinas relacionadas con el arte del diseño, nos conduce a estirar la práctica hacia atrás y a darle una gran importancia al proceso de diseño del proceso, el cual sería el equivalente de la planificación de la clase. Esto nos conduce a privilegiar la planificación con respecto a la evaluación, y a privilegiar el proceso con respecto a los resultados.

\section{Escribir}

Para socializar el libreto con los pares es preciso escribir. Claro, también podría hacerse por medio del discurso oral, pero nosotros hemos privilegiado el discurso escrito. Este nos da la oportunidad de pensar dos veces qué es lo que queremos socializar. Y nos obliga a poner en el lenguaje escrito las ideas que tenemos sobre el proceso. Nuestros pares, además, tienen una base para hacer su retroalimentación. El maestro debe reconocer que reflexionar sobre su práctica exige rigor y disciplina sostenida, y que es preciso dejar atrás el miedo que genera el papel en blanco. Se abandona el lugar común de "llenar las parcelaciones o los formatos". Escribir, entre otras cosas, es una tecnología para poner afuera nuestro pensamiento y ordenarlo.

Pero la escritura se cualifica en la medida en que es acompañada y fruto de un proceso de lectura de textos que complementen y amplíen el horizonte de la investigación. Es así como se revisaron 
y estudiaron textos y teorías sobre los temas de lectura, escritura, trabajo en equipo, diseño, competencias lingüísticas, documentos normativos oficiales, informes de otras experiencias de investigación.

Cada maestro lleva por escrito un Diario de Campo, donde registra su sentir frente al desarrollo de su propia práctica y del proceso de la investigación como trabajo colectivo. También elabora un escrito en el que consigna su reflexión frente a los diseños que propone, a sus puestas en escena y al registro audiovisual de éstas. Se escribe, asimismo, un documento colectivo en las reflexiones y trabajos de todo el equipo. En el aula, se escriben Protocolos que soporten la memoria del proceso y se filman en vídeo las puestas en escena. También hay registro audiovisual de las sesiones de trabajo y socialización del grupo docente del proyecto de investigación.

El primer producto de la investigación es que formó un grupo de docentes de aula lectores y escritores.

\section{Socializar}

El proceso de socialización potencia la reflexión que cada maestro ha hecho, con la retroalimentación de sus pares. Y ocurre en el escenario de lo que hemos llamado un taller de reflexión. La palabra taller hace alusión al carácter constructivista del trabajo que allí se realiza. Se trata de una construcción cooperativa de conocimiento. Durante las socializaciones los maestros presentan sus "papeles de trabajo", los cuales son leídos, analizados y retroalimentados por el grupo de investigación de manera periódica, dejando una videograbación del taller.

El propósito de la metodología es lograr identificar y poner en evidencia los supuestos que subyacen a la práctica, y los factores que obstaculizan el proceso de aprendizaje, para proponer alternativas de cambio. Sin embargo, pocas veces uno como individuo es consciente de esos supuestos. Es en el diálogo con el otro que se pueden identificar esos supuestos, y es en el diálogo como pueden construirse alternativas. Si el maestro investigador toma en serio la retroalimentación de sus pares, normalmente debe volver a reescribir sus diseños antes de la puesta en escena. Cada cual está en libertad de tomar de esta retroalimentación lo que le parezca razonable.

\section{El Trabajo en Equipo: la Interlocución Crítica}

Un segundo nivel de socialización, más cercano y cerrado al interior del proyecto, lo constituye la construcción de un equipo de trabajo. Aquí socializar es entendido como interactuar, y es en la interacción con los otros donde se construye conocimiento.

Al hacer un balance del camino recorrido hasta el momento en esta experiencia investigativa, vemos que el trabajo en equipo es la clave metodológica del proyecto. Se ha conformado un grupo de trabajo que ha generado su propia dinámica, donde el diálogo se ha constituido en la herramienta fundamental para la reflexión individual y colectiva. Esto ha llevado a los maestros a ser más conscientes de los procesos que se viven al interior del aula en las diferentes disciplinas y a reconocer el valor de la interdisciplinariedad. Es así como se han comenzado a vislumbrar ejes comunes que atañen a la labor pedagógica, al igual que especificidades que surgen de las diferentes personalidades de los docentes, de sus experiencias previas, de su didáctica.

Los maestros, al permitirnos fracturar aquellos espacios íntimos que hemos construido en el aula, como en una especie de refugio, en donde hemos hecho las cosas a nuestra manera, hemos decidido abandonar la aparente seguridad de ese espacio cerrado para lanzarnos a establecer un diálogo con el otro, en un espacio abierto en donde ese par solidario se nos ofrece como un espejo que nos devuelve sus imágenes para ayudarnos a exhumar nuestros presupuestos, y

\footnotetext{
"El aprendizaje en equipo es vital porque la unidad fundamental de apren dizaje en las organizaciones modernas no es el individuo sino el equipo". Peter Senge 1992.
} 
ayudarnos a construir nuevas maneras de ver $y$ de actuar como seres humanos y como profesionales, en el ámbito escolar.

El monólogo interno que se teje paralelo al diálogo se constituye en elemento esencial de crecimiento. Es alrededor de la construcción colectiva de diferentes visiones que podemos llegar a vislumbrar un escenario más integral de nuestras vivencias como personas y como maestros.

La disciplina del aprendizaje en equipo, tal como la plantea Peter Senge en su libro La Quinta Disciplina, comienza con el "diálogo" que es la capacidad que tienen los miembros del equipo de "suspender los supuestos", para poder ingresar en un "auténtico pensamiento conjunto" ${ }^{\prime \prime 4}$. Para los griegos, 'dia-logos' quería decir el libre flujo del significado a través del grupo, lo cual permitía al mismo tiempo descubrir percepciones que no se alcanzaban en forma individual.

El intercambio de significados que se ha generado al interior del equipo pone en evidencia las particularidades de cada maestro y, en ocasiones, suscita tensiones entre maneras de ver y de actuar. $\mathrm{Al}$ comienzo parece una especie de caos polifónico que refleja la pluralidad de voces pero, a medida que avanza el intercambio, con el ánimo de construir un saber colectivo, se comienza a percibir la ventaja de una interlocución constructiva y crítica.

La expresión "interlocución crítica entre pares" se ha tomado de Fabio Jurado, el cual la define como "ese atreverse a socializar la experiencia con una actitud dispuesta a remover, si es el caso, dispositivos que pueden no haber sido los más apropiados en la descripción analítica" (Jurado 1999: 70).

Otra de las ventajas del trabajo en equipo es que permite contrarrestar la fragmentación y el aislamiento en que se encuentran los maestros cuando están dedicados al trabajo de aula. El espacio común de interlocución se convierte en una oportunidad para recorrer el laberinto de la investigación en equipo, revisar los libretos y los roles, mirarse en los espejos que son los otros, y entretejer nuevas significaciones en torno a la práctica docente. Visualizamos esta metodología como una estrategia bifronte, de cualificación profesional y de reconstrucción de la institución escolar, a la vez, en y desde nuestro propio ámbito de trabajo. La hemos denominado Aula Abierta.

Al reflexionar críticamente sobre nuestras propias prácticas pedagógicas, y sobre las de nuestros compañeros, estamos aprendiendo constantemente una nueva manera de percibir nuestra labor dentro del aula. Estamos aprendiendo a escribir sobre lo que hacemos, a exponerlo con sencillez ante nuestros compañeros y a escuchar pacientemente sus observaciones y sugerencias. Es por ello que nos hemos declarado maestros aprendices 5 . La tolerancia ha adquirido un nuevo significado para nosotros: aceptar al otro como es escuchar lo que dice sin prevención, respetar su idea y su camino, criticar sin lastimar, sin ofender, sólo para crecer; dialogar pero escuchando, acortando distancias, construyendo puentes.

Es esta la manera como hemos comenzado a romper el mito de la privacidad de nuestras aulas, y como hemos comenzado a superar la fragmentación y el aislamiento en que nos encontramos los maestros. Hemos decidido exponernos, en el doble sentido que tiene esta palabra. Nos exponemos, porque asumimos los riesgos propios de la crítica. Y nos exponemos porque sacamos fuera de nuestras aulas lo que somos y lo que hacemos para construir un horizonte compartido.

\footnotetext{
Senge, Peter. La Quinta Disciplina: el arte y la práctica de la organización abierta al aprendizaje. Fd, Barcelona. Granica, 1992: 20. Aprender: adquirir el conocimiento de una cosa; aprendiz: persona que
aprende un arte u oficio.
} 
Por lo anterior es que podremos afirmar que una de las ideas directrices y una de las fortalezas indiscutibles de esta experiencia investigativa interdisciplinaria del proyecto Alúna, ha sido, sin lugar a dudas, el aprendizaje en equipo como un proceso de construcción cooperativa de conocimiento entre pares profesionales, que se reúnen para reflexionar, dialogar, analizar y comprender aquellos problemás que comparten en su oficio y profesión, pero sobre los cuales muy pocas veces se dialoga'.

Uno de los aprendizajes más importantes de nuestro proyecto ha sido el de trabajar en equipo. Nos hemos abierto a la posibilidad de dejarnos complementar por el otro. Hemos dejado atrás los miedos y las prevenciones. Nos abrimos sinceramente a los compañeros para que nos vean como somos y cómo actuamos en el aula, y dejamos que nos aporten al quehacer pedagógico. Reconocemos como interlocutor válido a nuestro par y dejamos que nos retroalimente, estamos dispuestos a escuchar y a cambiar. El trabajo en equipo es necesario, es fundamental. Si todos tuviésemos ese don de aceptar nuestros errores, avanzaríamos mucho más en el conocimiento y nuestro crecimiento sería mayor.

El poder entregarse al ejercicio de escuchar al otro, escuchar lo que piensa, siente, vive, cómo interpreta el texto, los aciertos y desaciertos, ver los bajonazos, el estado de ánimo, las aceleradas y por qué no, las escapadas de muchos de nosotros, es parte del proceso. Es genial ver cómo somos maestros, seres que sentimos y nos desvivimos por lo nuestro, a pesar de lo que digan. Para esto hemos nacido, con nuestro trabajo nos identificamos plenamente y cada momento que compartimos con los compañeros es un aprender a vivir, sentir y escuchar lo valioso que tiene el otro.

Cada uno de nosotros se ha metido a su manera en el laberinto de la investigación, y a pesar de nuestras diferentes visiones de mundo, hemos sabido elaborar estrategias comunes para encontrar una

\footnotetext{
6 Ávila, Rafael. La utopia de los PEl en el laberinto escolar. Bogotá. Uni-
} versidad Pedagógica Nacional-Colciencias, 1999. salida en equipo. A través de las vivencias en Alúna, cada investigador ha podido continuar construyendo ese puente sobre el cual nuestro río de la vida lentamente va fluyendo. Este proceso de aprendizaje al interior de cada uno de nosotros como miembros del proyecto, ha moldeado nuestro ser a partir de una experiencia colectiva. Ya nunca podremos ser los que antes fuimos.

\section{Comparar}

La información socializada es procesada desde diferentes frentes de análisis para evidenciar puntos convergentes y divergentes en las diferentes experiencias. Se escuchan y contrastan los diversos puntos de vista y la variedad de concepciones acerca de cómo debe ser el acto pedagógico. Se reconocen las convergencias y se evidencian aquellas que emergen como fortalezas, como factores facilitadores del aprendizaje. De la misma manera, se señalan las divergencias y se les analiza en su dimensión de facilitadoras u obstaculizadoras de los procesos de enseñanza-aprendizaje.

\section{Generalizar}

Una vez que se han puesto en evidencia los supuestos que permean la práctica docente, se buscan los puntos positivos convergentes del análisis, para señalarlos como relaciones regulares y recurrentes que permiten pasar a un nivel de mayor generalidad.

\section{Proponer}

Con base en los resultados de la generalización, se pueden sentar las bases para elaborar estrategias alternativas de diseño y ejecución de la práctica pedagógica, que permitan mejorar los resultados.

\section{Poner en escena}

La metáfora del teatro nos lleva a concebir al maestro como actor que pone en escena un libreto del cual es autor. $Y$ ya hemos señalado que como autor, puede atribuirse un rol protagónico, o puede distribuir el protagonismo entre sus estudiantes. Puede 
diseñar un libreto en el cual él es el único actor, o en el que sus estudiantes actúan con un papel activo. Puede salir al escenario o actuar entre bambalinas como consueta discreto. Son múltiples las modalidades de actuación. Pero, además, como director de la puesta en escena, tiene que adelantarse a prever y organizar el ambiente escenográfico (J. Dewey) la luminotecnia, los telones de fondo, $y$ el instrumental requerido para el trabajo. El maestro es un organizador de actores, de procesos, de ambientes y de herramientas.

\section{Auto-observarse en el registro audiovisual}

Los autores de la metodología hemos diseñado una manera de objetivar la práctica con la ayuda de una herramienta tecnológica: la videograbación. Son muchas las sorpresas que nos hemos dado al vernos en la videograbación. Pone en jaque la imagen que tenemos de nosotros mismos. Nos revela los tics, las muletillas, los movimientos en falso, la ausencia de organización, los estudiantes que se automarginan del proceso, etc. En fin, es un soporte para volver a reflexionar sobre nuestra práctica.

Como resultado de esta reflexión, a partir del video, viene un nuevo ejercicio escritural: lo hemos llamado paper, por la connotación de este término en inglés de documento de trabajo. Allí contamos cómo nos vimos en el video, qué fortalezas y qué debilidades encontramos en la puesta en escena y cuáles, a nuestro juicio, serían los reajustes que habría que hacer para mejorar.

Viene de nuevo la socialización. Distribuimos los papers con anterioridad al taller de reflexión para su lectura previa. Y luego, en el escenario del taller, viene la interlocución crítica, y la recolección de retroalimentación. Una vez más, cada maestro investigador se siente en libertad de recoger lo que le parece razonable. Se deja un registro audiovisual del taller.

\section{Elaboración del informe de ciclo}

Para cerrar el ciclo, el grupo se distribuye el trabajo para construir un informe de ciclo, equivalente a un informe de avance en cualquier proceso de investigación. Este también es un ejercicio escritural, esta vez a muchas manos, y sobre todo a muchos cerebros. El informe se concibe como un verdadero trabajo de grupo, en el cual cada uno de los maestros investigadores debe aportar su contribución. En este informe se tratan de organizar los principales aprendizajes del proceso.

\section{Un Ciclo de Alúna}

Hemos mostrado cómo una metáfora nos ha trasladado (metáfora significa traslación) desde una concepción de la práctica pedagógica como acción de "dictar clase" a una concepción de la misma como diseño de un libreto y puesta en escena, dos categorías que se refieren mutuamente. ¿Cómo convertir esta concepción en procedimiento, teniendo en cuenta la dimensión colectiva de la reflexión como trabajo en equipo? EI ciclo procedimental que vamos a presentar no nació hecho de una vez, fue el resultado de un borrador que contenía lo esencial, que se fue puliendo a partir de la práctica. Todos los pasos son necesarios para convertir nuestra concepción en procedimiento:

1. Diseño de los libretos para la puesta en escena de cada maestro investigador. Es el momento de planificación de la "clase".

2. Socialización de los libretos en el Taller de reflexión, con el fin de recibir retroalimentación por parte de los pares (audio grabado).

3. Reajuste y reescritura del diseño, con base en la retroalimentación.

4. Puesta en escena del libreto, simultáneamente registrada en vídeo por un técnico en videograbación.

5. Auto-observación de la puesta en escena, con la ayuda del registro audiovisual.

6. Elaboración de un paper que recoge las principales conclusiones de ese proceso de auto-análisis. 
7. Distribución de los papers a todos los miembros del equipo para su lectura, previa al Taller de reflexión.

8. Presentación de muestras de la videograbación y lectura de los papers, por parte de cada uno de los investigadores, ante todos los pares, con el fin de recoger retroalimentación y proceder a una reflexión colectiva, en un espacio que se ha denominado "talleres de reflexión". Videograbación de todo el taller.

9. Elaboración colectiva del informe correspondiente a este ciclo, con base en los siguientes insumos: registro del taller de reflexión sobre diseños, registro del taller de reflexión sobre los papers. Con la elaboración de este informe se cierra lo que hemos denominado "un ciclo" de Alúna.

\section{Inicio del siguiente ciclo.}

El grupo combina formas de trabajo individual con formas de trabajo grupal. Cuando los miembros del grupo están trabajando individualmente en el diseño, en su clase, o en la elaboración de sus papers, están en un momento de dispersión. Cuando los miembros del grupo se reúnen, en los talleres de reflexión, para trabajar colectivamente sus diseños o sus papers, e intercambiar apreciaciones mutuas, están en un momento de integración. La combinación de los procesos de trabajo individual -en la dispersión-, con los trabajos grupales - en la integración-, es lo que hemos llamado un ciclo de trabajo. El objeto específico de la investigación de Alúna son las prácticas pedagógicas de formación de lectores y escritores, sin embargo el concepto final de la interventoría de la entidad financiadora del proyecto concluyó que esta propuesta metodológica puede considerarse como herramienta de cualificación permanente de la práctica docente in-situ.

Los Obstáculos

Dos obstáculos, de marca mayor, se atraviesan en el proceso de modernización de nuestras instituciones educativas y de la práctica docente ${ }^{7}$. Uno tiene que ver con las políticas de formacióncualificación de los maestros, y otro tiene que ver con el imaginario dominante en las organizaciones magisteriales.

El primer obstáculo puede describirse como sigue: son, cada vez, más los investigadores, los maestros formadores de maestros, los directivos docentes y los diseñadores de políticas, que reconocen los procesos de cualificación de los maestros como una de las variables más importantes para hacer frente a los retos y a las expectativas, cada vez más complejas, que plantean las sociedades modernas a la educación, entre ellas merecen nombrarse las no poco exigentes, de la calidad y la equidad.

Sin embargo, son contadas con los dedos de una mano, las instituciones educativas que poseen políticas y programas de cualificación permanente de sus maestros. En la mayoría de los casos son los maestros, movidos por el interés de superarse, los que deben sacar de su ya exiguo salario el dinero necesario para participar en programas de cualificación ofrecidos, casi siempre, por instituciones universitarias. Esto parece sorprendente en un momento en el cual las teorías organizacionales y gerenciales se ponen de acuerdo en que el capital más importante de una empresa es el cognitivo, y su más importante inversión la que se hace en la cualificación permanente de sus empleados.

Los más tolerantes, muy pocos, conceden permisos y negocian horarios, bajo la presión permanente de maestros que solicitan autorización para participar en tal o cual proceso de cualificación. Para lo cual, obviamente, deben abandonar el recinto escolar y suspender sus actividades $y$ responsabilidades cotidianas. Al menos, cuando las actividades de cualificación se cruzan con los horarios propios de las instituciones educativas.

\footnotetext{
No queremos insinuar que sean los únicas obstáculos. Son aquellos sobre los cuales queremos centrar la atención en este trahajo.
} 
El segundo obstáculo, tiene que ver con el hecho de que los maestros parecen apresados en una aparente paradoja: quieren promover un cambio cultural diferido, cambiando a los estudiantes para que cambie la siguiente generación, pero se resisten, consciente o inconscientemente, a cuestionarse a sí mismos, y a provocar un primer cambio cultural en sí mismos. Son muchos ya los resultados de investigación que demuestran que los obstáculos de la educación radican más en la insuficiente preparación profesional de los maestros que en la insuficiencia de talento por parte de los estudiantes y que, aún más grave, la deserción escolar no es un simple accidente del proceso, sino un resultado de la cultura escolar vigente.

Los maestros investigadores del proyecto estamos convencidos de que esta metodología, probada a partir de la experiencia de campo, presenta los rasgos de una alternativa metodológica, innovadora y creativa, para salvar los dos obstáculos mencionados arriba. Primero porque soluciona el problema de la cualificación permanente de los docentes in situ, es decir: sin sacarlos de su ámbito institucional y por ende, $\sin$ producir los traumatismos provocados por los procesos de cualificación desde afuera. $Y$ segundo, porque resuelve la paradoja del cambio cultural diferido, al estar diseñada para que el cambio cultural comience con el mejoramiento de las prácticas pedagógicas de los maestros. Deseamos proponer que el punto de partida más importante para experiencias similares es el de "no cambiar a los otros sino cambiar nosotros".

La premisa de la racionalidad técnica es el supuesto fundacional del modelo vigente de formación profesional. Esta premisa, "durante mucho tiempo ajena a un examen crítico", puede formularse como sigue: que la competencia profesional resulta de una aplicación del conocimiento producido por las diferentes disciplinas científicas a los problemas propios de su práctica. Profesional, según este modelo, es el que sabe hacer uso del conocimiento científico para resolver los problemas a los cuales tiene que enfrentarse en su práctica.
La racionalidad técnica no es otra cosa que una epistemología de la práctica, como la llama Donald Schön (1992). Es decir: una cierta manera de concebir la práctica profesional, que se revela al examinar la estructura de los currículos de formación profesional: primero, un vasto "menú" de conocimientos provenientes de los más diversos campos disciplinarios (unos 506 semestres), y luego, en los últimos semestres, iniciaciones tímidas a la "aplicación", ojo a la palabra, de esos conocimientos a los problemas propios de su campo de acción. La racionalidad técnica, epistemología de la práctica que más abunda en este tipo de centros (superiores de formación), considera la competencia profesional como la aplicación del conocimiento privilegiado a los problemas instrumentales de la práctica, "(Schön 1992: 9).

La alternativa metodológica que aquí proponemos como una auténtica innovación, se apoya en los trabajos de Donald Schön y es una metodología de formación para una práctica reflexiva, semejante a la formación para la práctica en profesiones como el arte, la arquitectura, el diseño industrial, y otras en las cuales sus talleres de formación básica están centrados en el arte del diseño. Como alternativa metodológica apela a otra epistemología de la práctica, que sustituye la premisa de la racionalidad técnica (aplicación de conocimientos producidos en otros campos disciplinarios) por la premisa de una racionalidad constructivista que elabora el conocimiento adecuado para resolver sus problemas, a partir de una reflexión colectiva de los pares sobre los dilemas de su práctica. Esta forma de reflexión colectiva puede considerarse también como una experimentación compartida y, en las tradiciones de formación profesional ya citadas, siempre ha estado acompañada por un tutor. "¿De qué otro modo pueden los Profesionales aprender a ser inteligentes, si no es precisamente a través de la reflexión sobre los dilemas de la práctica?" (Schön: 11). 
ÁVILA, Rafael y CAMARGO, Marina, La Utopía de los PEI en el Laberinto Escolar. Santa Fe Bogotá: COLCIENCIAS CIUP - UPN - PIIE y Antropos, 1999.

ÁVILA, Rafael. La Educación y el Proyecto de la Modernidad. Santa Fe de Bogotá: Siglo XXI. Colección Pedagogía, 1998.

La Cultura: Modos de Comprensión e Investigación. Santa Fe de Bogotá: Siglo XXI. Colección Pedagogía, 1998.

BARTHE, Raquel. Claves para hacer Fracasar la Enseñanza del Lenguaje y la Literatura. Tomado de la revista digital Bitácora. www bitácora.net

BOGOYA, Daniel y otros. Competencias y Proyecto Pedagógico. Santa Fe de Bogotá: Universidad Nacional de Colombia. Unibiblos, 2000.

BRUNER, Jerome. La Educación: Puerta de la Cultura.

CAllAO, Francisco. "El Desarrollo del Lenguaje y la Capacidad Cognoscitiva". En: Alegría de Enseñar. Año 1. No.5

CASTILLO, Mauricio. Manual para la Formación de Investigadores. Santa Fe de Bogotá: Magisterio, 1999.

COLL, César. Acción, Interacción y Construcción en Situaciones Educativas. Madrid: Paidós, 1996.

Colombia: Al filo de la oportunidad, Misión, ciencia, educación y desarrollo. Tomo 1, Colección de documentos. Presidencia de la República

CHOMSKY, Noam. El Lenguaje y el Entendimiento. México: Planeta-Agostini, 1992.

DíAZ, Âlvaro. Aproximación al Texto Escrito. Medellín: Universidad de Antioquia, 1999.

FANDIÑO, Eduardo. Facultad de Derecho. Universidad de los Andes. Inédito, 2001.

FERNÁNDEZ, Juan. Concepto y Límites del Derecho Penal. Bogotá: Temis, 1992.

GARCIA, Enrique y RODRÍGUEZ Héctor. El Maestro y los Métodos de Enseñanza. México: Trillas, 1999.

GEERTZ, Clifford. La Interpretación de las Culturas

Barcelona: Gedisa, 1993.

GOODMAN, Kenneth. On Reading. New Cork: Scholastic Inc., 1996.
IARAMIILO, Adriana y NEGRET, Juan Carlos. "La Lengua Escrita y el Constructivismo". En: Alegría de Enseñar. Volumen 3, No. 11, Abril 1992.

JURADO, Fabio. Investigación, Escritura, y Educación: el Lenguaje y la Literatura en la Transformación de la Escuela. Facultad de Ciencias Humanas, Bogotá: Universidad Nacional de Colombia, 1999.

LEONE, Juan Pascual. Piaget, Vygotski y la Función del Símbolo. Pedagogias constructivistas, pedagogias activas y desarrollo humano. Memorias.

I Encuentro Internacional y IV Nacional. Universidad de Manizales, RED y CINDE, 1997.

MARIÑO, Milagros. Experiencias de Innovación en la Enseñanza de la Lectura y Escritura. Parte IV. Tomado de VIII Encuentro de Innovadores e Investigadores en Educación. CAB. Bogotá, 2000.

MINISTERIO DE EDUCACIÓN NACIONAL. Lengua Castellana: Lineamientos Curriculares. Santa Fe de Bogotá: Magisterio, 1998.

NICHOLS, Michael. El Arte Perdido de Escuchar. Aprender a Comprendernos y a Mejorar Nuestras Relaciones. Barcelona: Urano, 1998.

NIETZSCHE. Friedrich. Así Hablaba Zaratustra. Bogotá: Panamericana, 1993.

PÉREZ, Héctor. Nuevas Tendencias de la Composición Escrita. Bogotá: Magisterio, 1999.

PIATEl.I., Massimo. Las Ganas de Estudiar. Cómo Conseguirlas y Disfrutar con Ellas. Barcelona: Crítica, 1992.

RODRIGO, María José y otros. Familia y Desarrollo Humano: Psicología y Educación. Madrid: Alianza, 1998.

SÁBATO, Ernesto. La Resistencia. Buenos Aires: Editorial Seix, 2000.

SENGE, Peter. La Quinta Disciplina: El Arte y la Práctica de la Organización Abierta al Aprendizaje. Barcelona: Granica, 1992.

SCHÖN, Donald. La Formación de Profesionales Reflexivos: Hacia un Nuevo Diseño de la Enseñanza y el Aprendizaje en las Profesiones. Barcelona: Paidós, 1992.

UNIVERSIDAD DISTRITAL FRANCISCO JOSÉ DE CALDAS. Maestría en Lingüística Aplicada a la Enseñanza del Inglés. Memorias Segundo Congreso Colombiano de Lectoescritura en Lengua Materna y Lengua Extranjera. Bogotá. 2001. 
VÁSQUEZ, Fernando. El Oficio de Maestro. Bogotá: Pontificia Universidad Javeriana, 2000.

ZULETA, Estanislao. "Sobre la Lectura". En: Sobre la idealización en la vida personal y colectiva. Bogotá: Procultura S.A., 1985.

El Elogio a la Dificultad y Otros Ensayos. Bogotá: Fundación Estanislao Zuleta, 1994.

Sobre la Idealización en la Vida Personal y Colectiva. Bogotá: Procultura, 1985.

\section{Diálogo del Conocimiento}

Los docentes del grupo ALÚNA con su propuesta de trabajo colocan al docente en un lugar importante y privilegiado socialmente, ya que se presentan como intelectuales estudiosos del hacer pedagógico. El grupo invita a través de la experiencia a creer en el otro maestro, a reflexionar desde la equivocación y particularmente a abrir las puertas del aula para dejarse conocer.

Cuando el aula se abre a los otros (maestros, estudiantes, amigos), se vuelve más interesante, porque se convierte en el lugar donde caben múltiples preguntas, donde nada está terminado, donde los proyectos, las ideas y los sueños son el común para cada día.

Todo este mundo se teje en ALÚNA, es decir, el colectivo interdisciplinar, el aula de clase y la vida escolar son miradas desde la complejidad para buscar consolidar uno de los primeros propósitos "La formación de lectores y escritores". EI grupo de docentes se pregunta y discute durante un buen tiempo: ¿cómo encontrar un lenguaje que acerque a las disciplinas en lo divergente?. Así, como equipo de formación permanente y rigurosos intelectuales encuentran que a través de la metáfora es posible comunicarse.

Surgen entonces, las metáforas del laberinto, la telaraña, los espejos, y el teatro entendidas como la búsqueda en la que se teje y desteje, se mira, se actúa, se preparan los libretos y se conversa todo el tiempo. Estas metáforas son maravillosas porque permiten a la escuela salir de un profundo silencio, $y$ a sus actores decir todo lo que tienen para comunicar. De esta manera el conocimiento escolar emerge de un continuo diálogo y deja ser un objeto que se encuentra en un lugar para ser aprehendido o incluso un objeto que poseen solo los especialistas o los sabios. Al ÚNA es una propuesta que muestra como se construye conocimiento en colectivo.

La construcción de la vida escolar desde el lenguaje, el conocimiento, la formación y la convivencia son objeto de investigación desde los actores de ALÚNA, que no se conforman con que el propósito de formar lectores y escritores sea tarea exclusiva de los estudiantes, sino que ellos confrontan de manera regular toda su experiencia desde la escritura. Aprenden a escribir escribiendo, a investigar investigando, a trabajar desde la complejidad con actores de diferentes disciplinas, pensamientos, actitudes y valores.

Para finalizar, los invito a preparar un próximo articulo que muestre la experiencia de formación lectora y escritora con estudiantes y a participar en otras redes de maestros como la del Grupo de Fomento de la CEPE y el Centro de Estudios e investigaciones de la ADE para enriquecer y divulgar la propuesta de formación de docentes.

\section{Fanny Landínez Gómez.}

Docente del IED. La Belleza Los Libertadores y docente investigadora de la CEPE.

landinezfe@hotmail.com 